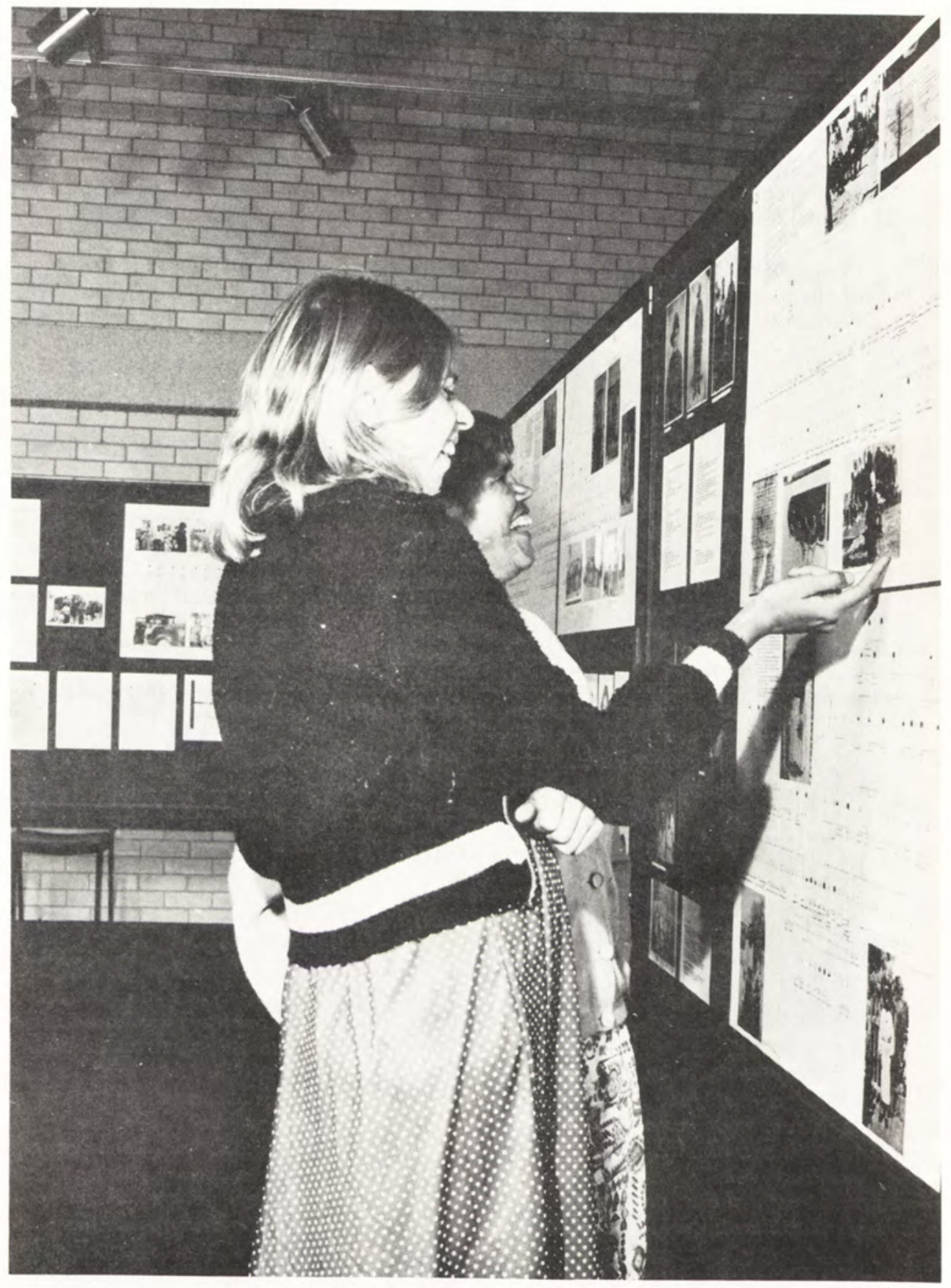

SWAS touring display, Albany, 1978.

Photograph by Geoff Lovell. 


\title{
THE SOUTH WEST ABORIGINAL STUDIES PROJECT
}

\author{
Lois Tilbrook
}

The South West Aboriginal Studies project (SWAS) began at the end of the 1976-77 financial year when limited funding became available, through the Department of Aboriginal Affairs, to the Aboriginal Teacher Education Program of Mount Lawley College. Over the next two years a research project was formulated to collect material on the history and cultural tradition of Aborigines of the south western region of Western Australia. This region is bounded by a line extending from the coastline south of the Murchison, in an arc south-eastwards to the southern coastline, east of Esperance. It corresponds to the 'circumcision line', south west of which circumcision was not practised, which formed a distinct sociocultural region. 1

The broad aims of the SWAS project were, to survey the available literature and documentation on Aborigines of the region, and produce a bibliography of relevant materials as a resource tool for future work, and to collect Aboriginal oral history and tradition, both to record this information before it was too late, and also ultimately to incorporate the material in descriptions of Aboriginal life from before European settlement up to the present.

The SWAS project was conceived from an awareness that little was written which put Aborigines of the south west into focus in the social history of the region or would assist in highlighting the problems this group of people face today. Existing works concentrate on the history of government administration of Aboriginal affairs ${ }^{2}$ and analyses of the social situation of this group of Aborigines reflect structural approaches and do not profess to convey a fuller understanding of the richer tradition of Aboriginal cultural life. ${ }^{3}$ Such works lack an Aboriginal input, except as the researched group. Other existing works do contain different material, though much more work in the area is needed. 4 A number of references to Aborigines also exist, scattered through government files, letters, diaries, manuscripts, and theses. Unpublished sources are largely inaccessible except to academic researchers, even when their existence is known. There is a need for this material to become more readily available for schools and community and health workers' courses, for others involved with Aboriginal groups, as well as for Aborigines themselves.

\section{The project}

The start of any research project is always difficult. We started in two directions: first we commenced a survey of the written material on Aborigines in the south west, including research into archival material, particularly for the initial period of European settlement of Western Australia in 1829 and for the 1897 period when the State obtained control of Aboriginal affairs from the British Colonial Office. 5 This latter period was of special interest as it represented the limit to which we could hope to collect oral accounts based on direct exposure; beyond that oral tradition would take over. Archival records might assist in making connections between the remembered past, and the experienced time leading to the present.

1 Elkin 1975:62; Berndt 1973:51.

2 Biskup 1973; Hasluck 1970.

3 Howard 1978; Berndt 1969.

4 Hallam 1975; Berndt and Berndt 1979.

5 Anna Haebich was appointed Academic Research Assistant at the inception of the SWAS project, and continues to maintain ties with it. A second Academic Research Assistant, Toni Creed, was employed for a limited period to research archival material. 
Secondly, fifteen Aborigines were employed to collect genealogies and oral family history. ${ }^{6}$ All of these people had family ties in the south west and were interested in collecting and recording their own genealogies and interviewing members of their families. We sought out mature people who could talk to older family members and adults, and whose own interest might be stimulated by having children who could benefit from the compilation of their family's history. The educational attainment of the collectors was not of major importance in their employment.

A training program was organised, teaching the collectors over two days how to construct genealogies, to tape record and how to interview. We thoroughly discussed the difficulties posed in recording information. One of our main concerns was that interviewees might refuse to co-operate when they saw research assistants taking notes especially as so many government agencies collected information from Aborigines who often felt powerless to resist them. Aborigines might also be worried by the use to which the material could be put. We thought that tape recorders might help to overcome this difficulty and that some people might also find tape recorders easier to use than taking notes. Some of the research assistants were not in the habit of writing extensively and found it an onerous task. Small cassette recorders were provided, together with an ample supply of tapes, and explicit instructions to find a quiet place in which to record interviews (this proved to be wishful thinking and background noise was a major difficulty in transcribing recordings).

Research assistants were employed on limited contracts for an equivalent fulltime period. They worked at their own pace in fulfilling the terms of their contracts. One person took six months. In this case collecting the information was a prolonged process, although the final production was amongst the most interesting of all the material collected. The difficulties experienced with this person were due mostly to the novelty of the research work rather than any lack of willingness. This flexible method of employment permitted people to put time in over weekends, or when they made family visits, without feeling they were being pressured. Also, it ensured that when a visit to relatives was made and a key person was not at home, the exercise could be repeated at another time, hopefully with better results for the research. It also enabled people to cope with other matters without their employment being affected by a period of relative non-productivity.

All research assistants were contacted shortly after they began collecting information. Their material was carefully gone through and help and advice given where necessary. Most importantly, this early contact indicated to the research assistants whether they were doing what was required and often provided the necessary confidence for them to carry on. The need to develop a sense of selfconfidence was felt most accutely by most of the people.

Progress payments were arranged to ensure that no one was out of pocket. For example, in making special visits to relatives living in the country where no mileage allowance was paid (because of budgetary limitations and also the task was seen as work combined with pleasure) a travelling subsidy was provided in some instances. The combination of interviews with family visits worked very well, and may even have stimulated more family contact where there was the added incentive of gleaning another piece of information to add to the jigsaw of a genealogy.

6 The following people were employed as research assistants: Moira Radloff; Leisha Eatts; Alicia Frinsina; Clarrie Ugle; Kayleen Hayward; Jean Lewis; Lex Collard; Lyn Narkle; Moreen McGlade; Phyllis McGuire; Vi Chitty; Eddie Bennell; Cherry Hayward; Joanna Wright; Godfrey Colbung. 


\section{Genealogies}

The genealogies were, for us, the most important material collected by the research assistants and also provided us with a sense of focus of the undertaking. Each genealogy had to be gone through meticulously, rough copies drawn up, inconsistencies detected and corrected. This frequently called for further information; muddles had to be sorted out, missing pieces had to be provided. We found that generation levels were frequently confused, and this was compounded by the use of common personal names within a family over several successive generations. We were particularly anxious to record anything that people could remember about ancestors who had lived during the nineteenth century, before memories faded.

The research assistants became deeply involved in constructing genealogies. Sometimes the smallest items of information were painstakingly gleaned from several people, who each knew a little but whose memories were vague. In piecing all this together surprising connections frequently emerged, such as being able to trace great-grandparents, or even grandparents where various members of a family in the past had been placed in institutions and family continuity lost.

We also searched for old photographs because of their value as a source of social documentation as well as being intrinsically interesting. The range and quality of photographs collected was tremendous. The oldest photographs were copied and returned to their owners, together with a new copy so that people could get some return for permitting us to use their possessions. At times, the only known photograph of a person was reproduced and preserved.

\section{Displays}

A number of people became involved in the SWAS project, because they had been contacted for information either directly by the research assistants or in directly by others who had heard of the project. A public display of genealogies, photographs and documents was held at Mount Lawley College in August 1978, fourteen months after the project began to enable people to see what we were doing.

We were all acutely conscious that a degree of rivalry and friction exists between certain Aboriginal groups in the south west, and we feared that the genealogies might be a centre of controversy. Consequently it was decided to restrict the display of genealogical material to pre-1914. People could trace their own family ties back to that point, and then use the trees to go further. In point of fact some people born later than 1914 appeared on the trees and here we relied on the advice of our research assistants. Furthermore, visitors to the display of ten insisted on bringing their genealogies down to the present, and it is likely we were over-concerned on this issue. Documents were also displayed. These were from the Aborigines Department files 1897 to 1910 , covering the period when the Aborigines Act of 1905 was introduced as State legislation. This was a particularly repressive piece of legislation which denied most fundamental rights to people classified as Aborigines in the wide terms of the Act. We also displayed photographs of people featured in genealogies and also of some of the documents. We were anxious to stress the positive contribution of Aborigines to the south west region and to counter negative images. For example, we took care to display evidence of Aborigines owning land.

We were worried about whether the display would be a success, fearing that only a handful of people would come to see it and that others might feel offended. Nothing like this had ever been attempted. In fact, we had underestimated the enthusiasm and interest of the public, especially Aborigines, and their fascination with genealogies and photographs. People came time and again, bringing different groups of relatives or friends with them. Fresh information and photographs were added, until the original genealogical charts looked like rough drafts. Many people 
obtained tremendous pleasure from the photographs and for the first time saw pictures of relatives or people they had heard about but never met. The genealogies traced relationships back in time further than many people realised and new links between families were discovered. An estimated 1,500-2,000 people visited the display, the majority of whom were Aborigines.

In response to repeated Aboriginal requests the genealogies were redrawn and the entire display was taken to three regional centres in the south west: Albany, 410 kilometres from Perth, Narrogin, 280 kilometres north of Albany, and Bunbury (on the coast), 200 kilometres west of Narrogin. Again we acquired much new information as people added to the genealogies. A greater interest by the non-Aboriginal population of Albany may be accounted for in part, by the venue. The display was mounted in the modern Albany Art Gallery, adjoining the public library, whereas in Narrogin and Bunbury we were in old halls situated away from other sites of cultural activity and even passing traffic. About 1,000 people, the vast majority Aborigines, visited the country touring display.

The project began to unwind after the country tour. During 1979 a series of smaller displays of selected family trees and photographs were prepared for such occasions as 'Back to Tammin' week in the eastern wheatbelt, and for the Narrogin Show. A small, semi-permanent, display was mounted in Mount Lawley College, and we received other requests which we could not respond to because we lacked financial resources. We have been requested to hold displays at a number of venues throughout 1980 and will be able to meet some of these. A very exciting feature of the genealogies, and also a major problem, is that they have to be re-drawn as additional material is gathered. This presents a problem in terms of labour and finance, as does re-printing the photographs which invariably deteriorate while on show. The physical task of mounting display materials onto boards or stands is also a major undertaking.

\section{What would we do differently?}

With the benefit of hindsight we would devote a longer period to training Aboriginal research assistants, even if this meant extending their employment and engaging fewer people. The two days we did spend were hopelessly inadequate to equip anyone to go out into the field. We realised this at the time, and hoped that this would be compensated for by the support and supervision given while the task was being carried out.

A longer period of initial training, say four days, followed by a further short period of two days soon after starting to collect information, would be time well spent. The opportunity to meet as a group to talk over difficulties encountered in initial research would be invaluable. Information collecting is not everyone's forte and interviewers in approaching others for information first have to overcome their own inhibitions. Some of the research assistants felt that they were imposing themselves on the interviewees by asking them to give freely of their time and information. Just to be aware that others shared these feelings, and to learn how they handled this, would have bolstered people's self-confidence. To see how others were faring in recording information, would also help them to overcome their own hesitancy.

The limited contracts worked out at the individual's own pace, with progress payments, suited everyone except the College bureaucracy which attempted to 'regularise payments' and to introduce 'standard part-time contracts'. This eventually resulted in an uneasy compromise, with less flexibility on our part but greater 'regularity' of payments, and some financial hardship for research assistants whose money was delayed between 'standard pay days'.

We advertised the research assistant positions and displays in the local newspapers, through Aboriginal organisations, and by word of mouth. Our recruitments 
eventuilly came from word of mouth contacts, and we could have saved money on newspaper advertising.

Every project has its own peculiar difficulties and problems. We were very fortunite in the choice of all those recruited to the project. We were also fortunate in the amount of overall freedom and flexibility we had in operating the project. This erabled us to respond to various needs as they arose. We had a place where visitors could be accommodated, cups of tea made, and interviews conducted if necessary. This was only possible because of the tolerance and understanding of those vorking in the Aboriginal Teacher Education Program who had to put up with streams of people, noise and other distractions on our behalf. Material resources were at our disposal such as stationery and clerical assistance. Other projects, with different regional variations and situational differences, would undoubtedly encounter other difficulties.

What has emerged from the project?

The SWAS project was a tremendously exciting and rewarding experience and continces to be so. The active involvement and support of Aborigines in Aboriginal research has been the most outstanding feature of the project. Their interest has not waned and since the displays many have visited us to go through the genealogie!.

The SWAS project has also been the impetus for a number of other projects. Material on Nyungar, the language spoken by Aborigines in the south west aimed at the general and Aboriginal public has been prepared for publication. ${ }^{7} \mathrm{~A}$ range of material on traditional Aboriginal life in the area before European settlemen: in 1829 and an annotated bibliography have also been prepared, along with a publication based on the display which is to be published with the support of the Abo:iginal Arts Board. Within Mount Lawley College south west Aboriginal material is now a feature of the courses offered, including a unit on the area in the Bactelor of Education.

Two volumes on Aborigines of the south west are being prepared as part of the Dictionary of Western Australians. This is an ambitious undertaking to compile a dictionary of all people in Western Australia from 1829 to 1914 as a contribution to the State's sesqui-centennial celebrations of 1979. Several volumes of this dictionary on various historical periods have already been published but virtually no sboriginal material is included in them. The reason for this is that entries have been dependent on individuals submitting written family details by filling out special forms. The publicity has been oriented towards those with an interest in the colorial past and in establishing family links with early arrivals to the state from 1825 onwards. The idea of a special Aboriginal volume did occur to the organisers of the project, but the research necessary at the time seemed daunting.

Tie source material on the Aborigines of the early period of the state's history is decumentary while for the latter periods it is mainly oral. As the two do not connect, except in rare instances, a separate volume on the $1829-1840$ period is being undertaken. 8 This volume poses a formidable task in the tracing of personalities and events where there are gross inconsistencies in spelling Aboriginal names ofter compounded by individuals having several names. Most of the available documentation reflects a lack of awareness of the significance of Aborigines in the evens described. It also reflects very lit tle clear understanding of Aboriginal culture or sccial organisation, and most of the entries involve males rather than females. Nevetheless, a fascinating picture of Aboriginal activity in the early days of Euro-

7 Liguist W.H. Douglas has prepared this material.

8 Jont compilers are S.J. Hallam and myself. 
pean settlement is being painstakingly constructed, particularly for the Perth-YorkPinjarra districts.

The second volume draws heavily on material contained in the genealogies, mostly collected by SWAS research assistants or during the displays. Here the main pitfalls are the vagaries of human memory, together with little available documentation and enormous difficulty in establishing any fit between written material, such as government files, and the genealogies. 9

This dictionary project is most exciting. The Aboriginal volumes will place Aborigines alongside other groups in the recent history of the State, at least for the south west. Hopefully, it will contribute to a greater general interest in, and appreciation of, the Aboriginal population of the region. Similar volumes are planned for other areas of the state. The difficulties encountered for each historical period, as well as regional variations, will prove a fascinating challenge.

As the SWAS project developed we found ourselves moving towards the idea of an Aboriginal resource centre where the genealogical material and family history could be kept together with a whole range of specific and general information on the south west and other areas. The experience of the SWAS project is evidence enough that Aborigines are willing to participate in activities which they see as relevant to themselves. The continuing in terest of non-Aboriginal organisations and groups indicates that they are also anxious to call upon resource material that they can relate to their own experience and knowledge. However, for the time being this cannot be achieved, mainly because of the cost involved.

It is hoped that the above account may be useful to others who may plan similar projects, and that they might benefit from our experience, and improve on our approach. 10

\section{MOUNT LAWLEY COLLEGE OF ADVANCED EDUCATION}

\section{BIBLIOGRAPHY}

Berndt, Ronald M. ed. Thinking about Aboriginal welfare: with particular reference to Western Australia. Nedlands, 1969.

'Aborigines of southwestern Australia: the past and the present', in D. Merrilees, W.C. Dix, S.J. Hallam, W.H. Douglas and R.M. Berndt, 'Aboriginal man in southwestem Australia', Journal of the Royal Society of Western Australia, 56(1 and 2), 1973:4455.

Berndt, Ronald M. and Catherine H. Berndt. eds. Aborigines of the West: their past and present. Perth, 1979.

Biskup, Peter. Not slaves, not citizens: the Aboriginal problem in Western Australia, 1898. 1954. St. Lucia, 1973.

Hallam, Sylvia J. Fire and hearth: a study of Aboriginal usage and European usurpation in south-western Australia. Canberra, 1975.

Hasluck, Paul. Black Australians: a survey of native policy in Western Australia 1829-1897. Melbourne, 1942, 1970.

Howard, Michael.ed. Whitefella business: Aborigines in Australian politics. Philadelphia, 1978.

Mollison, Bill and Carol Everitt. The Tasmanian Aborigines and their descendants. Hobart, 1978.

9 Joint compilers are Anna Haebich and myself.

10 We are aware of the work in this area carried out by Mollison and Everitt 1978. 